\section{Addition of clonidine and fentanyl to epidural blockade with $0.5 \%$ bupivacaine}

To the Editor:

Clonidine, an alpha ${ }_{2}$ agonist produces variable analgesia when given epidurally 1,2 but without respiratory depression. ${ }^{2,3}$ Synergy between epidural opioids and clonidine in producing analgesia has also been reported. ${ }^{2}$ In a double-blinded, randomised study, 26 patients undergoing major gynaecological surgery received lumbar epidural block with $17 \mathrm{ml} 0.5 \%$ plain bupivacaine. In addition, to evaluate the extent of the synergy, they received epidurally:

Group 1 - saline $0.9 \% 2 \mathrm{ml}$

Group 2 - clonidine $150 \mu \mathrm{g}$ made up to $2 \mathrm{ml}$ with $0.9 \%$ saline

Group 3 - fentanyl $100 \mu \mathrm{g}(2 \mathrm{ml})$ or

Group 4 - clonidine $75 \mu \mathrm{g}$ plus fentanyl $50 \mu \mathrm{g}$ made up to $2 \mathrm{ml}$ with $0.9 \%$ saline

No patient had received any analgesia for at least 24 $\mathrm{hr}$ before surgery. All were premedicated with diazepam $10 \mathrm{mg}$ po two hours before surgery.

In no group was analgesia sufficient for surgery produced. Most patients required general anaesthesia. The duration of analgesia ( $\mathrm{min}$ ) from completion of the epidural block until patients required further analgesia in the four groups is shown in the Table.

TABLE

\begin{tabular}{llll}
\hline Group 1 & \multicolumn{1}{c}{ Group 2 } & Group 3 & Group 4 \\
\hline $\begin{array}{l}\text { Number of patients } \\
6\end{array}$ & 7 & 6 \\
$\begin{array}{l}\text { Mean (range) } \\
399.2(220.5-795)\end{array}$ & $471.3(345-720)$ & $322.9(205-405)$ & $488.3(345-805)$ \\
$\begin{array}{l}\text { Standard deviation } \\
\text { 238.8 }\end{array} \quad 143.2$ & 71.8 & 162.5 \\
\hline
\end{tabular}

Although the mean duration of analgesia did not differ among the four groups, patients in Group 4 (clonidine $75 \mu \mathrm{g}$ plus fentanyl $50 \mu \mathrm{g}$ ) had the longest duration of analgesia that was nearly three hours longer than the mean duration of analgesia experienced by patients in Group 3 (fentanyl $100 \mu \mathrm{g}$ ). This suggests that the dose of epidural fentanyl may be reduced by the use of concurrent epidural clonidine.

Julian C.S. Murphy M MED

Edward A. Shipton PhD

Ivan Havlik PhD
Hermanus S. Schoeman DSc*

Departments of Anaesthesia and Pharmacology

University of Witwatersrand

Private Bag 23140

Joubert Park 2044

South Africa

*Medical University of Southern Africa

REFERENCES

1 Maze M, Tranquilli $W$. Alpha $a_{2}$ adrenoceptor agonists: defining the role in clinical anaesthesia. Anesthesiology 1991; 74: 581-605.

2 Bloor BC. Clonidine and other alpha 2 adrenergic agonists: an important new drug class for the perioperative period. Seminars in Anaesthesia, 1988; 7: 170-7.

3 Sperry RJ, Bailey PL, Pace NL, Eldrege S, Johnson K, Stanley $T H$. Clonidine does not depress the ventilatory response to $\mathrm{CO}_{2}$ in man. Anesth Analg 1990; 70: S383. 